\title{
A ROUPA DA RUA: PRECONCEITO LINGUÍSTICO EM DISCURSO
}

\author{
THE STREET CLOTHING: LANGUAGE PREJUDICE IN DISCOURSE
}

\author{
Soraya Maria Romano Pacífico', Michel Luís da Cruz Ramos Leandro \\ ${ }^{1}$ Universidade de São Paulo (USP), São Paulo, SP, Brasil \\ smrpacifico@ffclrp.usp.br ; michel.leandro@usp.br
}

Recebido em 29 nov. 2019

Aceito em 15 dez. 2019

Resumo: Este artigo está fundamentado na Análise do Discurso pecheuxtiana. $O$ trabalho foi construído com o objetivo de interpretar o discurso de sujeitos-alunos do Ensino Médio, de uma escola particular de Ribeirão Preto - SP, sobre preconceito linguístico. Segundo a Análise do Discurso, as condições de produção, que compreendem a relação dos interlocutores sempre afetada pela ideologia, o contexto da enunciação e o contexto sócio-histórico são fundamentais para a construção dos sentidos. Por isso, é importante destacar que os interlocutores, nesse caso, sujeitoprofessor e sujeitos-alunos discursivizaram sobre língua, linguagem, discurso e preconceito linguístico, dentro e fora da escola, sem que um único sentido sobre a temática fosse imposto. Foram lidos vários textos, especialmente, o livro de Marcos Bagno, Preconceito linguístico: o que é, como se faz; documentário, vídeo e palestra sobre língua/linguagem foram assistidos. Após o acesso a esses textos, iniciou-se a coleta de dados e constituição do corpus. Os sujeitos-alunos produziram seminários e realizaram prova escrita acerca da temática. Para este artigo, serão analisados recortes das provas escritas. Os resultados mostram que os sujeitos-alunos (re)conhecem o preconceito linguístico e argumentam contra ele, embora, muitas vezes, filiem-se à formação discursiva dominante que reforça a legitimidade de uma língua correta. Diante disso, entendemos que as práticas de ensino de língua têm de colocar em funcionamento as variedades linguísticas que a constituem, de modo a desnaturalizar a visão reducionista e preconceituosa de língua ideal, correta, padrão, ou seja, a língua da escola.

Palavras-chave: Discurso. Preconceito linguístico. Sujeito. Ensino.

\begin{abstract}
This article is based on the pecheuxtian Discourse Analysis. The work was built with the objective of interpreting the discourse of high school students from a private school in Ribeirão Preto $\mathrm{SP}$, about linguistic prejudice. According to Discourse Analysis, the conditions of production, which comprise the relationship of the interlocutors always affected by ideology, the context of enunciation and the socio-historical context are fundamental for the construction of the meanings. Therefore, it is important to highlight that the interlocutors, in this case, subject-teacher and subject-students, discursivized about language, discourse and linguistic prejudice, inside and outside the school, without the imposition of a single meaning. Several texts have been read, especially Marcos Bagno's book, Linguistic prejudice: what it is, how it is done; documentary, video and language talk were watched. After accessing these texts, data collection and corpus constitution began. The student-subjects produced seminars and conducted written test about the theme. For this article, clippings of written tests will be analyzed. The results show that student-subjects (re) know linguistic prejudice and argue against it, although they often join the dominant discursive formation that reinforces the legitimacy of a correct language. Given this, we understand that language teaching practices have to put into operation the linguistic varieties that use it, in order to denaturalize the reductionist and impaired view of the ideal, correct, standard language, that is, the school language.
\end{abstract}

Keywords: Discourse. Linguistic prejudice. Subject. Teaching. 


\section{INTRODUÇÃO}

Sua língua era um depósito de sombras retorcidas, com versos cobertos de hera e sarjetas que abriam asas sobre nós. (Manoel de Barros, 1980).

O ensino das normas gramaticais possibilita aos sujeitos-alunos se depararem com uma variedade da língua que nem sempre faz parte do seu cotidiano. A escola, por sua vez, tende a impor as regras linguísticas em suas práticas pedagógicas, principalmente, na disciplina de Língua Portuguesa, deixando de lado uma discussão fundamental, qual seja, a língua como uma estrutura de poder.

Marcos Bagno (1999) argumenta que há, na escola, um círculo vicioso que sustenta o preconceito linguístico atrelado a outro círculo vicioso que é o da injustiça social. O círculo vicioso do preconceito linguístico é formado pela união de três elementos que, ironicamente, o autor designa de "Santíssima Trindade" (BAGNO, 1999, p. 72), a saber: a gramática tradicional, os métodos tradicionais de ensino e os livros didáticos. Desse modo:

[...] a gramática tradicional inspira a prática de ensino, que por sua vez provoca o surgimento da indústria do livro didático, cujos autores - fechando o círculo - recorrem à gramática tradicional como fonte de concepções e teorias sobre a língua. (BAGNO, 1999, p. 75).

Observa-se que é um círculo vicioso que limita a possibilidade de a escola trabalhar com as diversas manifestações de linguagem, ou, na maioria das vezes, provoca a reprodução do discurso de que existe uma maneira "certa/correta" de falar e escrever. Esse discurso é sustentado pelo livro didático, que solicita aos sujeitosalunos, em suas atividades, que corrijam determinada variedade linguística segundo a norma-padrão da língua - por exemplo, uma tirinha em que há o uso de abreviações típicas do internetês - ou ainda, quando os livros didáticos trazem tirinhas da Turma da Mônica com as falas do Chico Bento e as atividades solicitam a correção da variedade usada pelo personagem a fim de que a norma padrão prevaleça, deixando-se de lado as questões semânticas, culturais e, especialmente, as relações desiguais de poder que envolvem os interlocutores em dada situação.

Diante desses métodos tradicionais de ensino, a escola contribui para que as aulas de língua/linguagem sejam vistas como difíceis e desinteressantes, como se a linguagem não fosse constitutiva dos sujeitos-alunos. Essa concepção de que a 
língua é um produto exterior ao sujeito sustenta um imaginário de que todo professor de língua portuguesa é um "corretor de desvios gramaticais", encarregados de ensinar o "jeito correto" de usar a língua, provocando o efeito de sentido de homogeneidade linguística, descartando as condições sócio-histórico-ideológicas que perpassam essa questão, silenciando o fato de o Brasil ser um país multilíngue e riquíssimo em variedades linguísticas. Esse silenciamento contribui para a reprodução do preconceito linguístico, isto é:

O preconceito linguístico está ligado, em boa medida à confusão que foi criada, no curso da história, entre língua e gramática normativa. Nossa tarefa mais urgente é desfazer essa confusão. Uma receita de bolo não é um bolo, o molde de um vestido não é um vestido, um mapa-múndi não é o mundo. Também a gramática não é a língua. A língua é um enorme iceberg flutuando no mar do tempo, e a gramática normativa é a tentativa de descrever apenas uma parcela mais visível dele, a chamada norma Culta. Essa descrição, é claro, tem seu valor e seus méritos, mas é parcial (no sentido literal e figurado do termo) e não pode ser autoritariamente aplicada a todo resto da língua - afinal, a ponta do iceberg que emerge representa apenas um quinto de do seu volume total. Mas é essa aplicação autoritária, intolerante e repressiva que impera na ideologia gerada pelo preconceito linguístico. (BAGNO, 1999, p. 9-10).

É esse modo autoritário, intolerante e repressivo que impera na concepção de língua una, imaculada, que sustenta o preconceito linguístico criticado por Bagno (1999). Essa questão precisa ser trabalhada na escola com o objetivo de levar os sujeitos-alunos a duvidarem dos discursos que excluem as variedades linguísticas presentes no país e, sem dúvida, dentro da escola, visto que, segundo o autor, os meios de comunicação (televisão, jornais, revistas, sites etc.) são os primeiros a produzirem um discurso sustentado pela ideologia dominante de que quem fala e escreve como a gramática determina terá mais chances de ascender socialmente, discurso que também provoca o mito de que "sujeitos sem instrução falam errado" e de que é "preciso saber gramática para falar e escrever bem", inclusive, reproduzindo um discurso ainda mais perigoso como o de que "brasileiro não sabe português, só em Portugal se fala bem português", sentidos esses que sustentam uma "subalternidade linguística" (BAGNO, 1999, p. 13), historicamente e ideologicamente (re)produzida nesses discursos, bem como fomentam a exclusão de quem não domina as regras gramaticais. São todos mitos discursivos sobre a língua/linguagem que Bagno (1999) busca desconstruir.

A partir dessas considerações, o objetivo deste artigo é analisar, por meio do dispositivo analítico-teórico da Análise de Discurso pecheuxtiana, o discurso de 
sujeitos-alunos do primeiro ano do Ensino Médio de uma escola particular de Ribeirão Preto - SP sobre o preconceito linguístico, observando quais os efeitos de sentidos sobre esse tema ecoam nos dizeres desses sujeitos, se os discursos deles reproduzem ou não o preconceito linguístico. Entendemos que se trata de um tema relevante no sentido de promover um ensino de língua portuguesa que leve em conta as variedades linguísticas que constituem a língua portuguesa falada no Brasil e, consequentemente, os brasileiros, posto que para a Análise do Discurso a linguagem é constitutiva do sujeito, não é simplesmente uma estrutura linguística que deve ser aprendida.

Sujeito, para a Análise do Discurso, é um efeito de sentido produzido por um indivíduo que, a partir de uma posição social é interpelado pela ideologia, filia-se a determinada formação discursiva ${ }^{1} \mathrm{e}$, tomado pela ilusão de ser a fonte do dizer (PÊCHEUX, 1995), (re)produz discursos. Importante ressaltar que tanto os sujeitos quanto as formações discursivas são heterogêneos, o que significa que não estamos tratando de pessoas e blocos de sentidos estáveis, unos. Ao contrário, o terreno da Análise do Discurso é movediço, está sempre em curso, em movimento, assim como os sujeitos e os sentidos. Interessa-nos, neste trabalho, refletir sobre a posição sujeito-aluno que produz sentidos sobre língua, linguagem e preconceito linguístico.

Fizemos um trabalho com sujeitos que cursam o Ensino Médio. A escolha dessa etapa escolar - 1ํ ano do Ensino Médio - deve-se ao fato de tratar-se de sujeitos-alunos que já passaram pela Educação Infantil, Ensino Fundamental e estiveram, desde os anos iniciais da escolarização, inseridos em um percurso que teve a língua/linguagem como um dos temas fundamentais de estudo, o que nem sempre significa que a discussão sobre variedade linguística e preconceito linguístico tenha sido feita nessas etapas escolares pelas quais eles passaram.

\section{SOBRE A METODOLOGIA E CONSTITUIÇÃO DO CORPUS}

As produções escritas dos sujeitos-alunos, última etapa do percurso metodológico que apresentaremos aqui, foram coletadas a partir de uma avaliação de língua portuguesa, que tinha o seguinte enunciado:

\footnotetext{
${ }^{1}$ Por formação discursiva entendemos, segundo Pêcheux (1997a), que se refere a tudo que pode e deve ser dito, em dado contexto sócio-histórico.
} 
Segundo o estudioso Mauricio Gnerre (1999, p. 6), "Uma variedade linguística vale o que valem na sociedade os seus falantes, isto é, vale como reflexo do poder da autoridade que eles têm nas relações econômicas e sociais". Com base nos estudos realizados em sala de aula, especialmente, o livro de Marcos Bagno, Preconceito linguístico: o que é, como se faz, argumente se você concorda ou não com Mauricio Gnerre e se você já sentiu como esse poder e autoridade estão relacionados ao preconceito linguístico e ao uso (ou não) da língua padrão.

Antes de apresentarmos os resultados da avaliação, é importante descrevermos em que condições de produção os sujeitos-alunos participaram dessa prova, visto que "[...] o laço que atrela as significações de um texto a suas condições sócio-históricas não é secundário, mas constitutivo das próprias significações" (BARONAS, 2011, p. 19). As condições de produção fazem parte da exterioridade linguística e podem ser agrupadas segundo as circunstâncias da enunciação (sentido estrito) e o contexto sócio-histórico-ideológico (sentido amplo), como preconiza Orlandi (2011).

Por ser assim, houve um percurso teórico-metodológico antes de chegarmos à avaliação escrita, conforme descreveremos. Nós, junto aos alunos, construímos atividades de leitura, discussão e interpretação dos textos selecionados. Como a Análise do Discurso postula, sujeitos e sentidos se constituem com o texto. Desse modo, os sentidos que os sujeitos-alunos interpretaram materializaram-se na língua e foram apresentados na modalidade oral, por meio de seminários grupais e, também, na modalidade escrita, por meio da avaliação escrita. Além do livro de Marcos Bagno (1999), assistimos com os alunos a vídeos nos quais múltiplas vozes discursivizam sobre língua, linguagem e discurso.

A priori, delineamos o objetivo de desnaturalizar o discurso sobre o preconceito linguístico, a fim de possibilitar aos sujeitos-alunos reconhecerem e valorizarem a diversidade da língua portuguesa. Colocamos em discurso e em disputa as seguintes questões: 1. O que é língua? 2. Existe um jeito correto de falar e escrever? 3. Para que servem as aulas de língua portuguesa?

As respostas foram escritas na lousa e, em geral, os discursos sobre língua reforçavam a formação discursiva dominante nas ciências positivistas, isto é, de que se trata do idioma de uma nação e/ou pessoa; a língua como um órgão do corpo humano; e, a língua como um sistema de regras. Em relação à segunda pergunta, todos os sujeitos-alunos argumentaram que existe um jeito certo de falar e escrever e que é para isso que existem as aulas de língua portuguesa, inclusive, algumas 
respostas filiavam-se à formação discursiva dominante, segundo a qual quem não "fala certo", também não "escreve certo".

Após essa etapa, a segunda consistiu em dividir os capítulos do livro Preconceito linguístico: o que é, como se faz?, de Marcos Bagno (1999) e atribuí-los aos grupos de alunos a fim de que eles fizessem a leitura e produzissem uma apresentação oral das interpretações que realizaram sobre a parte do livro que ficou sob a responsabilidade de cada grupo. Essa apresentação deveria ser feita por meio de um recurso artístico (teatro, música, memes, slides, vídeo, encenação etc.). A leitura da imagem da capa (fotografia do sogro, sogra e genro do autor) e do prefácio do livro foram feitas por nós como um modo de iniciar a temática do livro.

Os seminários foram multimodais, alguns grupos apresentaram trechos da obra em slides, produziram cartazes expositivos e resumos escritos para entregarem aos colegas da sala; outros produziram paródias, dramatizações, memes, vídeos e até jogos de "torta na cara" e "caça ao tesouro". Ao final de toda apresentação, retomávamos os conceitos importantes levantados nos seminários por meio de uma roda de conversa, para que os sujeitos-alunos pudessem tirar suas dúvidas a respeito de partes do livro que não compreenderam, possibilitando um momento de constituição de sujeitos e sentidos.

Para a terceira etapa do trabalho, assistimos a três vídeos: dois vídeos ${ }^{2}$ com falas sobre preconceito linguístico, de Leandro Roque de Oliveira, mais conhecido pelo nome artístico Emicida, rapper, cantor e compositor brasileiro, e o documentário ${ }^{3}$ Língua: Vidas em português, inclusive, a sala transformou-se em cinema com direito a pipoca e sucos.

Todos os vídeos abordaram a questão da variedade linguística e do preconceito linguístico, apresentando uma discussão sobre a língua em relação ao poder, como nos apresenta Gnerre (2009, p. 5) ao dizer que "as pessoas falam para serem 'ouvidas', às vezes, para serem respeitadas e também para exercer uma influência no ambiente em que realizam os atos linguísticos", ou seja, a palavra tem poder e sabe-se que somente uma parte da sociedade tem acesso à língua de prestígio - a chamada língua "padrão" - e a escola tende a excluir os sujeitos-alunos em relação à língua deles porque não aceita a variedade linguística com a qual o

\footnotetext{
${ }^{2}$ Disponível em: https://www.youtube.com/watch?v=QlhsiMWT-eQ. Acesso em: 14 nov. 2019. Disponível em: https://www.youtube.com/watch?v=YDDeBLxKwrs\&t=81s. Acesso em: 14 nov. 2019. ${ }^{3}$ Disponível em: https://www.youtube.com/watch?v=JBmLzbjmhhg. Acesso em: 14 nov. 2019.
} 
sujeito se identifica se ela for diferente daquela legitimada pelas instituições de poder.

O documentário Língua: vidas em português, filmado em 2001 e lançado nos cinemas brasileiros no ano de 2004, conta com a participação de falantes da língua portuguesa que moram em Portugal, Moçambique, Índia, França, Japão e Brasil. O documentário aborda o cotidiano e a cultura desses sujeitos, assim como os modos de uso da língua portuguesa, em que as variações linguísticas e a diversidade de pronúncia são marcantes. Nomes ilustres como José Saramago (escritor português), João Ubaldo Ribeiro (escritor brasileiro), Martinho da Vila (cantor e compositor brasileiro), Teresa Salgueiro (cantora portuguesa do grupo Madredeus) e Mia Couto (escritor moçambicano) também participam do vídeo e contribuem para a discussão sobre a língua portuguesa.

Caminhando para as últimas atividades desse percurso que se iniciou na escola e foi para além dela, pois os sujeitos participaram do evento ocorrido no Serviço Social do Comércio - Sesc - Ribeirão - SP, em que eles puderam assistir à palestra Palavra é poder, da poeta, cantora e atriz, Elisa Lucinda. Durante a palestra, a artista defendeu a palavra como um direito humano de livre expressão, cultura e cidadania, negado à população negra, visto que os negros ainda são sujeitos silenciados pelo racismo estrutural (ALMEIDA, 2019) que assola as relações sociais, como, por exemplo, a literatura de autoria de mulheres negras que tende a sofrer a interdição da política literária impedindo que a produção literária das autoras negras circule nos vários setores da sociedade (LEANDRO, 2019). Lucinda argumentou sobre o poder da palavra em curar, libertar e transformar o humano; porém, a escritora não silenciou que, contraditoriamente, a palavra tem o poder de ferir, excluir e matar.

Por fim, o quinto e último movimento pedagógico consistiu na aplicação de um questionário composto de três questões discursivo-argumentativas acerca do que foi estudado sobre variação e preconceito linguístico, entre elas, a pergunta já citada que serviu para análise deste artigo. Vale ressaltar que antes da aplicação da avaliação, assistimos a mais um vídeo, dessa vez, sobre o Museu da Língua Portuguesa - Idiomaterno ${ }^{4}$ - da Estação da Luz, em São Paulo - SP, como mais uma possibilidade de ampliar o acesso dos sujeitos-alunos ao arquivo, entendido,

\footnotetext{
${ }^{4}$ Disponível em: https://www.youtube.com/watch?v=2LNopxcBVms. Acesso em 14 nov. 2019.
} 
conforme Pêcheux (2010), como um campo de documentos disponíveis sobre uma questão, ou seja, os sujeitos-alunos estiveram em contato e em confronto com vários sentidos sobre o funcionamento da linguagem e do preconceito linguístico.

Esse foi o percurso para a constituição do nosso corpus. A nosso ver, vários sentidos foram mobilizados para que a subjetividade se constituísse, de acordo, sem dúvida, com as condições de produção de que dispúnhamos, o que interfere nas produções que serão analisadas, a seguir.

\section{O DISCURSO DOS SUJEITOS-ALUNOS SOBRE PRECONCEITO LINGUÍSTICO: SENTIDOS EM MOVIMENTO}

Ao concordarmos com Orlandi (1996, p. 64) em que "interpretar é compreender, ou seja, explicitar o modo como um objeto produz sentidos, o que resulta em saber que o sentido sempre pode ser outro", partimos do princípio que o mesmo objeto simbólico pode ser interpretado, diferentemente, por diferentes sujeitos, os quais são cindidos, divididos, heterogêneos, e, a escola tem de (re)conhecer e respeitar a constituição da subjetividade que se dá pela linguagem.

Entretanto, as relações de subjetividade, na instituição escolar, nem sempre respeitam as diferenças de sujeitos e sentidos. Pacífico (2012) argumenta que há uma prática pedagógica ainda dominante que não oferece condições para que os sujeitos-alunos assumam a responsabilidade pelo dizer, uma vez que uma voz de autoridade, geralmente representada pelo livro didático, já determinou o sentido que pode e deve circular, em sala de aula.

Discordando dessa prática pedagógica autoritária, ao construirmos e percorrermos os cinco momentos pedagógicos relatados, nos quais a questão da variedade e do preconceito linguístico teceu a discursividade, entendemos que colocamos em funcionamento o discurso do tipo polêmico (ORLANDI, 2011), posto que não impusemos uma única leitura, seja ela do livro didático ou, no caso, do livro de Marcos Bagno. Para Orlandi (2011), no discurso polêmico, os interlocutores podem disputar o objeto discursivo e a polissemia é permitida. Nessa direção, outras manifestações de linguagem, outras vozes, outros pontos de vista foram colocados em discurso, dentro e fora da escola, a fim de que um arquivo sobre a temática pudesse ser acessado e que os sujeitos-alunos tivessem condições discursivas para 
identificarem-se ou desidentificarem-se (PÊCHEUX, 1995) com determinados sentidos e, a partir desse processo de subjetivação, novos sentidos pudessem ser produzidos no fio discursivo.

Envolvidos em tantas possibilidades de interpretação e afetados por diferentes vozes acerca da noção de erro na língua, uma das formulações que mais provocaram disputa dos sentidos foi: Então vale tudo? Segundo Bagno (1999, p. 128) "tudo vale alguma coisa, mas esse valor vai depender de uma série de fatores", visto que o sujeito ao utilizar em sua fala, por exemplo, gírias, precisa levar em consideração quem é seu interlocutor, qual relação de poder está em jogo na interlocução, qual é a aceitabilidade dessa variante linguística, pois:

Uma das principais tarefas do professor de língua é conscientizar seu aluno de que a língua é como um grande guarda-roupa onde é possível encontrar todo tipo de vestimenta. Ninguém vai só de maiô fazer compras num shopping-center, nem vai entrar na praia, num dia de sol quente, usando terno de lã, chapéu de feltro e luvas... (BAGNO, 1999, p. 129).

A "roupa" da língua - metáfora de Bagno - é um ponto importante para as análises, já que muitos sujeitos-alunos argumentaram a partir dessa formação discursiva. As análises serão apresentadas a partir de recortes que, para a Análise do Discurso devem ser entendidos como partes do funcionamento discursivo e não como fragmentos de enunciados. Os recortes mantêm relação com o funcionamento do corpus e serão apresentados tal como foram escritos, pois os escritos indiciam um modo de ser sujeito na língua(gem), conforme veremos. Destacamos que, para nossa análise, o percurso argumentativo assumido pelos sujeitos-alunos mereceu nossa atenção especial. Isso porque entendemos que:

[...] Para argumentar, então, entendemos que o sujeito tem de ter acesso ao interdiscurso, "ao todo complexo com dominante das formações discursivas" para poder identificar-se com determinados sentidos, para inscrever-se em uma ou em várias formações discursivas e, sendo assim, exercer seu direito de argumentação. Percorrer o interdiscurso significa estar em contato com os sentidos já produzidos sobre determinado assunto, mas não simplesmente em contato, é preciso que o sujeito realize gestos de interpretação. Em outras palavras, para argumentar é preciso, antes, interpretar, pois se não houver interpretação, como poderá o sujeito disputar os sentidos? (PACÍFICO, 2016, p. 197).

Consideramos que o direito à argumentação acerca de um tema tão polêmico merece destaque no contexto escolar, pois os sentidos produzidos pelos sujeitosalunos podem contribuir para uma reflexão mais consistente sobre ensino de língua, conforme observaremos nos recortes: 
Recorte 1: Nascidos em uma nascença de julgamento, acabados tendo que nos autoaperfeiçoar para que possamos não sofrermos com tais consequências causadas pela linguagem diferenciadas de muitos (já que possuímos um linguajá muitos distinto, pois variam da nossa cultura para criar nossa linguá) e quando utilizamos desse nosso linguajá cultural acabamos sofrendo um certo tipo de preconceito linguístico, já que para muitos uma linguá com sotaque, palavras diferentes, palavras antecipadas, fora do padrão formal, acaba por si só sendo uma linguaja de "vagabundo". Então por isso existe um preconceito raizado na linguá do povo, em que vale quem diz, como falá Gnerre.

Nesse recorte, o sujeito-aluno mobiliza sentidos sobre a língua/linguagem provocando o leitor com as formas escritas "linguajá, linguá, falá", palavras acentuadas na última sílaba com a supressão do "r", remetendo à modalidade oral da língua. Nesse caso, temos um sujeito que escreve talvez como ele "fala", ou muitos que ele conhece "falam". Essa escrita, que também traz marcas de uma escrita mais elaborada, como lemos em "nascença de julgamento, acabados tendo que nos autoaperfeiçoar para que possamos..."; "palavras diferentes, palavras antecipadas, fora do padrão formal...”, indicia-nos um sujeito autorizado, por si próprio, ou pelo professor a expressar um modo peculiar de linguagem que aponta para a polissemia da língua, bem como para um sujeito que se constitui dentro e fora da escola com variedades linguísticas diferentes, pelas quais ele é afetado e deixa pistas disso em seu dizer, marcando que a coexistência das variedades linguísticas é possível e deve ser respeitada. Outra possibilidade de interpretação dessa escrita pode ser que o sujeito identifica-se com uma variedade linguística, percebe 0 preconceito que está "raizado na linguá" e, devido ao fato de ele estar aprendendo a norma padrão, na escola, e ter ciência de que essa é a variante de prestígio, ele coloca no seu texto as palavras mais elaboradas, indiciando um outro saber sobre a língua.

O sujeito discursiviza que, desde a "nascença" o humano é julgado e, para enfrentar os julgamentos, aperfeiçoa a sua linguagem a fim de não "sofrer com as consequências causadas pela linguagem diferenciada", que está "fora do padrão formal", isto é, os "linguajá muito distintos" tendem a sofrer preconceito linguístico, seja por causa do sotaque, vocabulários outros e plurais, "palavras antecipadas", que ressoam sentidos de que quando o sujeito utiliza a língua "sem pensar", no fluxo da linguagem o "erro" pode aparecer. Podemos dizer que temos em jogo a errância da língua, que aparece como aquilo que é falho, desse modo, "[...] o erro emerge 
como aquilo que deve ser expurgado, corrigido, afastado ou ultrapassado" (ALMEIDA, 2018, p. 18).

Almeida (2018) argumenta em sua tese sobre a epistemologia da errância, apontando que, na historiografia, o sedentário é aquele que instaura projetos para si e para a natureza e isso condiciona o movimento em torno dos mesmos pontos, assim, para o sedentário o erro deve ser corrigido, afastado, porque pode ressoar sentidos que vão em direção ao fracasso da colheita. Já o nômade precisa conhecer os melhores pontos para estabelecer uma posição temporária, em que uma escolha errada pode custar a vida de todo seu grupo. E o errante por caminhar no mundo sem projetos, não erra e nem acerta, o que há é uma movência errante entre as partes que constituem língua, discurso e sujeito. Assim:

\begin{abstract}
A língua essencial deve descartar sotaques, jogos de linguagem, regionalismos e usos descompromissados da língua. A língua atemporal exige engajamento, um certo senso de dívida e gratidão com a exatidão da "boa fala", tornando-se crivo ideológico que separa classes e autoriza a fala. A ilusão de estabelecimento de vínculos atemporais e universais sedentariza a significação através de um empreendimento de catalogação que busca adequar perfeitamente o mundo em essências necessárias, compreensíveis e instrumentalizáveis. $O$ conhecimento ocidental moderno se torna, portanto, uma máquina de sedentarização (controle dos sentidos) que apaga a errância e sobrescreve-a com necessidades que ilusoriamente apagam o erro e instauram uma língua correta, ajustada e eficiente. (ALMEIDA, 2018, p. 119).
\end{abstract}

Pode-se observar que a necessidade de um mundo "semanticamente estabilizado" faz com que a língua seja instrumentalizada por meio de uma "máquina de sedentarização" (PÊCHEUX, 1997b, p. 34) como é o caso das regras gramaticas ensinadas na escola e vistas como a "língua correta", que "enraíza a linguá" dos povos e, por não "errar", fazem dos "errantes" os "vagabundos" da língua que "vagam", erradios sem rumo; estes, portanto, por vestirem a "roupa da língua como andarilhos", mostram os rasgos possíveis e apresentam a língua como opaca e passível de deslizes, inclusive como prófugos fazem-se na língua gaudérios, porque se deixam movimentar nessa língua(gem) que é sempre condição material do discurso, pois é onde o sentido se constitui sócio-historicamente.

Recorte 2: Há pouco tempo sofri preconceito linguístico por utilizar a palavra "transparência", não entendi muito na hora o porquê de a diretora brigar comigo por uma palavra que a advogada do presidente do Brasil utilizou em uma de suas entrevistas no canal SBT, mas depois entendi que não importa o jeito que o negro da periferia tente se expressar, infelizmente as pessoas sempre irão criticar. Qualquer gíria que o branco burguês fala entra pro dicionário, mas, cada palavra do dicionário dita por um negro de classe baixa é gíria. Após as aulas do professor e ter lido o livro "Preconceito Linguístico", eu passei a "vestir a roupa" e comecei a falar um pouco mais formal e fiz até um texto no Facebook sobre a palestra que fui na Câmara 
Municipal da nossa cidade, pois sei que isso trazerá status para mim. Da próxima veiz vou falar com a diretora como a gramática manda. Mas eu gosto mesmo é da minha roupa da rua, já que aí eu sou eu mesmo.

No recorte 2, o sujeito-aluno discursiviza o preconceito sofrido em relação ao vocabulário usado com a diretora da escola e, nessa relação desigual de poder, quem perde é ele, pois somente quem está do lado mais frágil da interlocução deve "adequar-se" à dada variante linguística, visto que há uma formação discursiva sustentada pela formação imaginária que naturaliza, pelo efeito da ideologia, questões desse tipo: "Quem é ele para falar assim comigo?" (PÊCHEUX, 1995, p. 82).

A palavra "transparência" utilizada pelo sujeito-aluno corre solta na língua usada por diversos grupos sociais e produz sentidos de cordialidade, uma certa honestidade e até mesmo compromisso com o diálogo entre os interlocutores; todavia, pelo fato de a diretora estar em outra formação discursiva e ser capturada pela ideologia dominante de "língua certa e errada", assim como pela relação desigual de poder e de saber supostamente estabelecida entre eles, essa palavra soa ofensiva e cabe ao sujeito-aluno "adequar-se" à situação de interação verbal; portanto, espera-se que seja feito uso da norma-padrão da língua.

As questões de negritude também não são silenciadas no discurso do sujeitoaluno e denunciam que o funcionamento do preconceito linguístico é afetado pelas questões de classe, raça e gênero, afinal, quando o "branco burguês" fala entra para o dicionário; por outro lado, a fala do negro de classe baixa é considerada gíria. Há um discurso muito difundido nas escolas que naturaliza que o conhecimento e domínio do léxico estão condicionados ao uso do dicionário, como se nesse instrumento linguístico repousasse a língua perfeita e completa. Sabemos que a língua não se esgota nos dicionários, nem funciona discursivamente nesse instrumento linguístico. Apesar disso, se a escola trabalhasse com outros tipos de dicionários, por exemplo, dicionários de gírias, de regionalismos, entre outros, a instituição estaria contribuindo para a crítica a uma visão dominante de língua una, pois a deslegitimação das variedades linguísticas não padrão e a falta de uma discussão acerca dessa imposição, tanto nos livros didáticos quanto no contexto escolar, de modo geral, provoca o efeito de que há sim uma "língua certa/culta" que deve ser usada por todos os falantes, do mesmo modo, em qualquer situação de interlocução. 
Pode-se observar que o sujeito trabalha com uma noção empírica atrelada a uma formação imaginária do que seja o sujeito branco e o sujeito negro; no entanto, sabe-se que a questão de raça influencia na valorização de uma variante linguística. Sobre isso, destacamos o exemplo da enxurrada de críticas negativas que o vestibular da Unicamp recebeu ao colocar em sua lista de obras literárias de Carolina Maria de Jesus e Os Racionais. Isso indicia que, mesmo quando não é o negro que traz a voz do negro, do favelado, do pobre e marginalizado para dentro dos espaços considerados de pertencimento somente aos grupos que detêm o poder, a resistência ao diferente irrompe, conforme as críticas ao vestibular apontam.

Porém, a resistência também se manifesta pela "manha" do oprimido ao "adequar" a sua linguagem à norma-padrão da língua quando escreve sobre o evento na Câmara Municipal em sua página social no Facebook. A respeito dessa "manha", Leandro (2019), com base em Freire (1968) defende que práticas discursivas manhosas podem ser compreendidas como efeitos de sentido dos sujeitos que fogem do esperado. É uma prática discursiva que pode ser observada pelos indícios linguísticos, quando um sujeito joga o jogo político, aparentemente, na posição de "bom sujeito" (PÊCHEUX, 1995, p. 215), “[...] todavia, é uma "manha”, uma possibilidade dada pela opacidade da linguagem, em que esse sujeito dissimula filiar-se a determinada região do sentido para "sobreviver" (LEANDRO, 2019, p. 162) às coerções sociais, nesse caso, ao preconceito linguístico, pois o sujeito desveste sua 'roupa da rua' para vestir a da gramática e, assim, ganhar um certo "status" social. Pelo jogo das formações imaginárias entendemos que é possível ao sujeito embrenhar-se em práticas discursivas manhosas.

Para nós, essa tomada de posição do sujeito em vestir a norma-padrão da língua para falar com a diretora, em oportunidade futura, ou escrever nas redes sociais, deve-se, sobretudo, aos cinco momentos pedagógicos aos quais ele teve acesso, função que defendemos que é da escola, isto é, a escola tem o dever de trabalhar as questões de poder que envolvem a língua(gem), com base em arquivos trabalhados em sala de aula.

Por fim, o sujeito discursiviza sua estratégia manhosa de que "da próxima veiz vou falar com a diretora como a gramática manda", utilizando a noção de “adequação" de Bagno (1999, p. 129). No entanto, ainda assim, não silencia que ele 
gosta é da "roupa da rua", pois é nessa "língua" que ele se sente confortável e se constitui subjetivamente. É isso que defendemos em relação ao trabalho com a língua(gem) na escola, ou seja, a instituição escolar deve considerar que uma das funções dela é garantir ao sujeito-aluno o poder de interagir nas mais variadas situações discursivas, garantir o acesso aos diferentes universos semânticos que são importantes em uma dada sociedade e cultura. Quando nos referimos a acesso à cultura, não restringimos o acesso à possibilidade de argumentar, por exemplo, sobre a democratização do acesso ao cinema em uma redação do Exame Nacional do Ensino Médio (ENEM 2019), mas sim, que os sujeitos-alunos tenham acesso aos mais variados livros, vozes, vídeos, filmes, cinemas, teatros, enfim, nas mais variadas situações em que eles possam ver e participar da língua em funcionamento, em discurso, promovendo a possibilidade de dar voz aos seus discursos e sentidos produzidos por meio dessas práticas (ORLANDI, 2012).

Recorte 03: Uma experiência que eu vivi do preconceito linguístico foi quando estava dialogando com meus pais e no meio disso usei gírias, meu pai simplesmente virou para a minha direção e falou que ele não era os meus coleguinhas da rua, pois ele era uma autoridade maior.

Nesse recorte é possível observar o efeito de sentido da "roupa da rua", metáfora que estamos utilizando para tratar da variedade linguística desprestigiada, em que o pai interdita o modo de falar do filho por meio de uma formação imaginária de ideal de língua, afinal, qual língua deveria "vestir" o filho para falar com o pai?

O sujeito-aluno discursiviza que no meio do diálogo com o pai utilizou gírias e é a partir desse uso que o estranhamento ocorre. Segundo Patriota (2009, p. 14-15):

Hoje, apesar de todo o preconceito que sempre a cercou (e cerca!), a gíria é um fenômeno que tem, cada vez mais, invadido a sociedade em seus mais diversos segmentos e níveis, constituindo uma forma particular de expressão, seja em seu aspecto mais fechado - a gíria de grupo - ou em seu aspecto de vulgarização - a gíria comum. Contudo ela ainda é amplamente relacionada aos jovens e seus grupos interacionais.

É esse preconceito que cerca o uso da gíria, como aponta Patriota (2009) que faz com que o pai não compreenda que, talvez, esse uso linguístico possa indiciar proximidade e, até mesmo afeto, nesse processo de interlocução pai/filho; todavia, o preconceito linguístico aparece e a autoridade também, impossibilitando a construção de um efeito de simetria na interlocução pai/filho, do mesmo modo como 
não houve na interlocução entre o sujeito que escreveu o recorte 2 e a diretora. Temos dois exemplos de funcionamento discursivo em que a língua da suposta voz de autoridade (diretora, pai) interdita um modo de ser sujeito em outra variedade linguística que não seja a padrão. Nesses casos, como escreve Coracini (2007), a língua materna funciona como língua madrasta, pois destitui o sujeito, que não usa a variedade linguística de prestígio, do seu lugar de pertencimento à língua materna.

Recorte 04: O preconceito linguístico não ocorreu comigo, mas sim com a minha irmã. Ela cria muitas palavras e outras vezes ela fala de modo que julgamos errado. No começo corrigíamos e falávamos para ela qual era a forma correra, porém, ela continua inventando palavras e hoje acostumamos e até mesmo nos divertimos, dizemos que é o "Dicionário da Y" do "mundinho dela". Y diz que fala assim mesmo cursando Física Médica porque adora ler poesia. O que posso dizer é que a língua é um mistério e está em constante mudança e quem sabe talvez se algumas palavras que ela inventa não entre para o dicionário, a gramática é uma caixinha de surpresas.

No recorte 4, encontramos a formação discursiva dominante sobre os usos errados da língua, a necessidade de corrigir as palavras inventadas pela irmã e, também, observamos um sujeito que desliza e migra para outra região do sentido, deixando de tratar a língua com rigidez ao afirmar que "a língua é um mistério e está em constante mudança", e que a "gramática é uma 'caixinha de surpresas'”. O sujeito, cindido como de fato é, movimenta-se no discurso e, ao escrever sobre a língua, de estática ele passa a considerá-la como elemento social, histórico e ideológico ao dar outra interpretação para a fala da irmã, visto que "quem sabe talvez se algumas palavras que ela inventa não entra para o dicionário", marcando a possibilidade do furo e da resistência em relação à imposição da gramática normativa.

Perini (1997) argumenta que as aulas de língua portuguesa, muitas vezes, se restringem ao estudo da gramática; no entanto, segundo esse pesquisador, "Ninguém, que eu saiba, conseguiu até hoje levar um aluno fraco em leitura ou redação a melhorar sensivelmente seu desempenho apenas por meio de instrução gramatical" (PERINI, 1997, p. 27-28), isso pode ser verificado, principalmente, nas séries inicias do Ensino Fundamental em que o ensino da gramática não contribui para que o sujeito-aluno se movimente na e com a linguagem e produza seus discursos e sentidos.

No Ensino Médio, inclusive, muitas escolas dividem a disciplina de língua portuguesa em Redação, Gramática e Literatura, como se fossem disciplinas 
distintas e a gramática fosse central para que o sujeito-aluno pudesse produzir redações e ler "bem" literatura, como critica Bagno (1999, p. 149).

A gramática tradicional permanece viva e forte porque, ao longo da história, ela deixou de ser apenas uma tentativa de explicação filosófica para os fenômenos da linguagem humana e foi transformada em mais um dos muitos elementos de dominação de uma parcela da sociedade sobre as demais.

É contra essa dominação que, segundo Bagno, a escola deve estar atenta, pois considerar a variedade linguística é democratizar a diversidade linguística que é constitutiva da língua. Perini (1997) diz que os sujeitos-professores que insistem em argumentar que a gramática ensina escrever melhor estão sempre fadados ao fracasso, pois prometem uma mercadoria que não poderão entregar. Para esse autor, "[...] deve-se estudar gramática para saber mais sobre o mundo; não para aplicá-la à solução de problemas práticos tais como ler ou escrever melhor" (PERINI, 1997, p. 55-56). Parece-nos que os discursos analisados neste artigo corroboram esse posicionamento de Perini.

\section{CONSIDERAÇÕES FINAIS}

A Análise do Discurso nos ensina que a ordem da língua é a do inatingível (GADET; PÊCHEUX, 2004). Com Barros (1980, p. 19) ficamos sabendo que "cada pássaro governa sua árvore, bastou que a família compreendesse esse 'arpejo das palavras'" da irmã para que essa inventividade não fosse vista como o que Leandro (2016) entende por "corpo-estranho", isto é, "[...] o que é estrangeiro e estranho ao corpo, o que não faz parte ou não é conhecido pelo sistema, aquilo que faz produzir sentidos e se move pela subjetividade a partir de um contexto sócio-histórico" (LEANDRO, 2016, p. 23); portanto, de corpo-estranho passa a ser um corpo-familiar quando a variedade linguística é trabalhada na escola.

Gadet e Pêcheux (2004, p. 51) formulam que "nada da poesia é estranho à língua. Nenhuma língua pode ser pensada completamente, se aí não se integra a possibilidade da poesia". Nesses termos, cabe à escola haver-se com a poesia da língua para que consiga escutar os rumores dela em deslocamento, pois muitos sujeitos-alunos ao terem que se adequar o tempo todo à gramática normativa não compreendem o trabalho com a linguagem em sentido amplo, ou seja, a escola 
atrela-se a um ensino que considera apenas a paráfrase e controla a polissemia. Nossa defesa é deslocar o ensino da língua do enfadonho (apenas a gramática normativa), da leitura e escrita parafrásticas, sem metáforas e polissemia, cravada na imagem de que o sentido deve ser um só para todos os sujeitos-alunos, para um ensino que considere o mistério da língua e as suas constantes mudanças, pois, como escreveram Gadet e Pêcheux (2004) é preciso que se brigue pela metáfora, e, nós acrescentamos, que se brigue pelas roupas da rua.

\section{REFERÊNCIAS}

BAGNO, M. Preconceito Linguístico: o que é, como se faz. São Paulo: Edições Loyola, 1999.

BARONAS, R. L. Ensaios em Análise em Discurso: questões analíticas-teóricas. São Carlos: EdUFSCar, 2011.

BARROS, M. Arranjos para assobio. Rio de Janeiro: Record, 1980.

CORACINI, M. J. A celebração do Outro: arquivo, memória e identidade. Campinas: Mercado das Letras, 2007.

FREIRE, P. Educação como prática da liberdade. Rio de Janeiro: Paz e Terra, 1967.

FREIRE, P. Pedagogia do oprimido. Rio de Janeiro: Paz e Terra, 1968.

GADET, F.; PÊCHEUX, M. A língua inatingível: o discurso na história da linguística. Tradução de Bethania Mariani e Maria Elizabeth C. de Mello. São Paulo: Pontes, 2004. Originalmente publicado em 1981.

GNERRE, M. Linguagem, escrita e poder. 3. ed. São Paulo: Martins Fontes, 2009.

LEANDRO, M. L. C. R. Autoria e Resistência: Carolina Maria de Jesus em discurso. 2019. Dissertação (Mestrado em Educação) - Faculdade de Filosofia, Ciências e Letras de Ribeirão Preto, Universidade de São Paulo, Ribeirão Preto, 2019.

LEANDRO, M. L. C. R. O "corpo-estranho" da poesia e a produção de sentidos na escola. 2016. Trabalho de Conclusão de Curso (Graduação em Pedagogia) Faculdade de Filosofia, Ciências e Letras de Ribeirão Preto, Universidade de São Paulo, Ribeirão Preto, 2016.

LíNGUA: Vidas em Português. Direção: Victor Lopes. Brasil; Portugal: Ancine, 2001. Documentário. 
ORLANDI, E. P. Análise de Discurso: princípios e procedimentos. Campinas: Pontes editores, 2011.

ORLANDI, E. P. Discurso e texto: formulação e circulação dos sentidos. Campinas: Pontes, 2001.

ORLANDI, E. P. Interpretação, autoria, leitura e efeitos do trabalho simbólico. Petrópolis: Vozes, 1996.

PACÍFICO, S. M. R. Argumentação e autoria nas redações de universitários: discurso e silêncio. Curitiba: Appris, 2012.

PACÍFICO, S. M. R. O direito à argumentação no contexto escolar. In: PIRIS, E. L.; FERREIRA, M, O. (org.). Discurso e argumentação: em múltiplos enfoques. [S. I.]: Grácio Editor, 2016. p. 191-212.

PATRIOTA, L. M. A gíria comum na interação em sala de aula. São Paulo: Cortez, 2009.

PÊCHEUX, M. Análise Automática do Discurso. In: GADET, F.; HAK, T. (org.). Por uma análise automática do discurso - uma introdução à obra de Michel Pêcheux. Tradução de Bethania S. Mariani et al. Campinas: UNICAMP, 1997a. p. 61-161.

PÊCHEUX, M. Ler o arquivo hoje. In: ORLANDI, E. P. (org.) et al. Gestos de leitura: da História no Discurso. Campinas: Editora da UNICAMP, 2010. p. 55-64.

PÊCHEUX, M. O Discurso: estrutura ou acontecimento. Tradução de Eni Puccinelli Orlandi. 2. ed. Campinas: Pontes, 1997b.

PÊCHEUX, M. Semântica e Discurso - uma crítica à afirmação do óbvio. Tradução de Eni Pulcinelli Orlandi et al. Campinas: Unicamp, 1995.

PERINI, M. A. Sofrendo a gramática: Ensaios sobre a linguagem. 3. ed. São Paulo: Ática, 1997.

\section{Sobre os autores}

\section{Soraya Maria Romano Pacífico}

Professora associada do Departamento de Educação, Informação e Comunicação da Faculdade de Filosofia, Ciências e Letras de Ribeirão Preto - USP. Formada em Letras, Mestre em Linguística e Língua Portuguesa- UNESP; Doutora em Ciências -FFCLRP/USP; Pós-Doutorado pela UNESPAraraquara, em 2013. Docente no curso de graduação em Pedagogia da FFCLRP/USP e dos Programas de Pós-Graduação em Psicologia e de Pós-Graduação em Educação, da FFCLRP/USP. Desenvolve pesquisas sobre Leitura, Escrita, Argumentação e Autoria. Atualmente, dedica-se ao projeto Argumentação e Subjetivação na Escola Básica: as práticas discursivoargumentativas no contexto escolar. Autora de livros e capítulos de livro sobre essas temáticas. 


\section{Michel Luís da Cruz Ramos Leandro}

Doutorando em Educação pela Universidade de São Paulo (FFCLRP-USP). Mestre em Educação pela Universidade de São Paulo (FFCLRP-USP) (2019). Especialista em Alfabetização e Letramento e Redação e Oratória pela Faculdade São Luís. Graduado em Letras pela Faculdade de Filosofia, Ciências e Letras de Ituverava (2012) e Pedagogia pela Universidade de São Paulo (2016). Atua como professor de Língua Portuguesa na Educação Básica da rede SESI. Participa do Grupo de Pesquisa "Discurso e memória: nos movimentos do sujeito" (GEDISME) filiado à Universidade de São Paulo e cadastrado junto ao Diretório de Grupos do CNPq. Tem interesse e participa de pesquisas ligadas à área de Linguística, em especial a Análise de Discurso pecheuxtiana, investigando, principalmente, os seguintes temas: escrita, autoria, leitura e políticas públicas educacionais. No momento trabalha com a questão das práticas pedagógicas contemporâneas de escrita no Ensino Médio investigando se elas promovem (ou não) gestos de autoria aos sujeitos-escolares (professores e estudantes) e a redação do Enem. 